\title{
Isolation and Identification of Group A Streptococcal Infection Among Slum Children in the Age Group of 5-15 Years in Chennai - One Year Prospective Study
}

\author{
S. Kalpana ${ }^{1}$, Jasmine S. Sundar ${ }^{1}$, S. Parameshwari ${ }^{1}$, \\ P. Kuganantham ${ }^{2}$, Jerard Maria Selvam ${ }^{3}$, Ms. S. Valarmathi ${ }^{1}$, \\ Manjula Datta ${ }^{4}$ \\ ${ }^{1}$ Department of Epidemiology, The Tamil Nadu Dr.M.G.R.Medical University, Guindy, Chennai, India, \\ ${ }^{2}$ Health Officer, Corporation of Chennai, ${ }^{3}$ Deputy Director, DPH, Chennai, ${ }^{4}$ Retd Professor, The \\ Tamil Nadu Dr.M.G.R.Medical University, Guindy, Chennai.
}

\begin{abstract}
Objective: To isolate Group A Streptococcal infection (GAS) from slum children in the age group of 5 to 10 years with or without evidence of throat infection dwelling in the slums of Chennai and to study their carrier state.

Methods: Children aged between 5-15 years from slum were enrolled in this study. Socio demographic details were collected and their clinical examinations were done to identify symptoms. Two throat swabs were collected from all the children irrespective of symptoms. Bacterial culture was carried out in blood agar and the isolation of GAS was confirmed using hemolysis on blood agar, streptococcal group identification kit and bacitracin sensitivity. Blood sample was tested for ASO antibody titre.

Findings: Group A streptococcus prevalence was isolated in $36 \%$ of slum population. Culture positive children were correlated with ASO antibody. Statistically significant correlation ( $p$-value $>0.001$ ) was observed between presence of antibody and culture positive. Recently infected children showed raised ASO antibody titre than the carrier. Major risk factors identified in GAS positive children were father's occupation, type of house, number of windows and the unhygienic conditions of the slum. $36 \%$ were infected with Group A Streptococcal infection, $9 \%$ infected with Group C, 6\% Group B, 1\% Group D, 0.1 and 0.3 Group F and Group G streptococcal infection.

Conclusion: The result shows that the prevalence of streptococcal infection was common among slum children but the prevalence of Group A streptococcus was high comparing to other groups of streptococcus. Socioeconomic status considered to be major associated risk factor for getting streptococcus infection.
\end{abstract}

Key words: Group A streptococcus, Socio Economic Status, Throat swab

\section{Introduction}

Group A Streptococci (GAS) is one of the most significant pathogens responsible for causing tonsillitis and pharyngitis in both children and young adults. Clinical diagnosis and culture for the organisms help in the diagnosis of throat infection due to GAS. It is difficult to distinguish clinically as streptococcal and nonstreptococcal infection of the throat and most of the physicians tend to over diagnose GAS infection and call for culture routinely. Though early diagnosis and treatment helps to prevent further complications such as rheumatic fever, acute glomerulonephritis and shortens the disease course and reduces the transmission of disease, but it may lead to unnecessary treatment with antibiotics in individuals who turn out negative on throat culture. The group A streptococcus (GAS) is a form of $\beta$-hemolytic Streptococcus responsible for most cases of sore throat/pharyngitis and rheumatic fever. Other types (B, C, D, F and G) may also cause throat infection. Sore throat remains a most common problem in children. In India isolation rates of GAS in children with pharyngitis have ranged from $4.2 \%$ to $13.7 \%$, which are comparable to the rates reported from developed countries. However, studies of carrier rates in the communities have not been done, and it is the only factor which reflects isolation from symptomatic children in out patient clinics. In closed and crowded communities the rates of isolation and spread of GAS infection may be much higher. The prevalence of asymptomatic carrier of GAS in different parts of India has been reported to lie in the range of $11.2-34 \%^{3,4}$. The potential aims of treatment for streptococcus are reduction of symptoms and prevention of suppurative and nonsuppurative streptococcal sequlae mainly acute rheumatic fever. Hence, a prospective study was conducted to study the isolation of Group A Streptococcal (GAS) infection among children in the age group 5 to 15 years with or without evidence of throat infection dwelling in the slums of South Chennai. 


\section{Methods}

Slums in Chennai corporation zones have been selected for this study. Six hundred children were enrolled after obtaining informed consent from the head of the household. Institutional Ethical Committee clearance was obtained for this study. All the children were screened for pharyngitis/tonsillitis and two throat swabs were collected from tonsillar area and posterior pharyngeal wall using sterile cotton swabs, and processed for the isolation of group A streptococci. Three $\mathrm{ml}$ of blood sample was collected to detect ASO antibody. Throat swabs were cultured in the $5 \%$ sheep blood agar plate for $24 \mathrm{hrs}$ at $37^{\circ} \mathrm{C}$ under $5-10$ per cent $\mathrm{CO}_{2}$. After the incubation period, GAS was identified and confirmed by haemolysis on blood agar, Gram stain, colony morphology, catalase test, bacitracin sensitivity $(0.04$ units/disc). Then, the isolates were further examined for Lancefield grouping with rapid latex test. ASO antibody titer was done using RHELAX ASO kit. Statistical analysis was carried out using SPSS Vr 17. SES were given in frequencies and percentage. Categorical variables were compared with the chi-square test. Student's t-test and ANOVA were used to compare the risk factors, clinical symptoms and culture.

\section{Results}

Baseline demographic details of the slum population are tabulated in table 1. It shows, $69 \%$ working as daily wage labourer, $81 \%$ nuclear family, $40 \%$ having one child, $36 \%$ having two children and $22 \%$ having more than 2 children, $32 \%$ of them living in Kutcha house, $84 \%$ using toilet for defecation, $57 \%$ using corporation water for drinking .

\begin{tabular}{|c|c|c|}
\hline Characteristics & Frequency & Percentage (\%) \\
\hline \multicolumn{3}{|l|}{ Age } \\
\hline $5-10 \mathrm{yrs}$ & 313 & 52 \\
\hline $11-15 y r s$ & 287 & 48 \\
\hline \multicolumn{3}{|l|}{ Sex } \\
\hline Male & 355 & 59 \\
\hline Female & 245 & 41 \\
\hline \multicolumn{3}{|l|}{ Parents occupation } \\
\hline Daily wages & 415 & 69 \\
\hline Business & 45 & 8 \\
\hline Fisheries & 67 & 11 \\
\hline Government sector & 24 & 3 \\
\hline Driver & 40 & 7 \\
\hline Painter & 9 & 2 \\
\hline \multicolumn{3}{|l|}{ Type of Family } \\
\hline Joint & 109 & 18 \\
\hline Nuclear & 491 & 82 \\
\hline \multicolumn{3}{|l|}{ No of siblings } \\
\hline "only" child & 252 & 42 \\
\hline 2 children & 232 & 39 \\
\hline 3 children & 71 & 12 \\
\hline 4children & 21 & 5 \\
\hline 5children & 6 & 1 \\
\hline 6children & 18 & 3 \\
\hline \multicolumn{3}{|l|}{ Type of House } \\
\hline Kutcha & 193 & 32 \\
\hline Pucca & 33 & 6 \\
\hline Semipucca & 374 & 62 \\
\hline \multicolumn{3}{|l|}{ Proper ventilation } \\
\hline Yes & 235 & 39 \\
\hline No & 365 & 61 \\
\hline \multicolumn{3}{|l|}{ Defecation } \\
\hline Toilet & 506 & 84 \\
\hline Open space & 94 & 16 \\
\hline \multicolumn{3}{|l|}{ Source of Drinking Water } \\
\hline Corporation water & 341 & 57 \\
\hline $\begin{array}{l}\text { Bore well /well/hand } \\
\text { pump }\end{array}$ & 259 & 43 \\
\hline
\end{tabular}

Table 1: Baseline demographic characteristics of the slum population 
Risk factors were compared with culture positive's, among the GAS positive's statistically significant association was seen with fathers occupation ( $\mathrm{p}$-value $0.014 \%$ ) type of house (p-value 0.045\%), Zone wise ( $\mathrm{p}$ value 0.000 ). Isolation of GAS rate was not significantly associated with number of children in the house, (pvalue 0.944 ), number of rooms (p-value 0.274$)$, Number of people sleeping in a room (p-value0.188), defecation (p-value 0.351 ) but significant association was found only with fathers occupation and number of windows ( $\mathrm{p}$ Value $-0.014,0.041$ ). Other factors such as age (p-value 0.158), type of family (p-value 0.852), source of drinking water (p-value-0.311),weight of the children $(0.281)$ and defecation $(0.305)$ was not statistically significant compared with GAS isolation.(table-2)

\begin{tabular}{|l|l|}
\hline Risk factors & $\mathbf{p}$-value \\
\hline Fathers occupation & $\mathbf{. 0 1 4}$ \\
\hline Type of family & .852 \\
\hline No of sibilings & .944 \\
\hline Type of house & .045 \\
\hline No of rooms & .274 \\
\hline $\begin{array}{l}\text { No of people } \\
\text { sleeping in a room }\end{array}$ & .188 \\
\hline Proper ventilation & .161 \\
\hline No of windows & $\mathbf{. 0 4 1}$ \\
\hline Defecation & .305 \\
\hline $\begin{array}{l}\text { Source of drinking } \\
\text { water }\end{array}$ & .311 \\
\hline Clinical symptoms & .401 \\
\hline Zone & $\mathbf{. 0 0 0}$ \\
\hline
\end{tabular}

Table-2: Comparison of risk factors with culture ( $\mathrm{p}$-value $>0.001$ considered as statistically significant)

There was a significant association between age of the children and culture positives ( $\mathrm{p}$-value >0.001). GAS infection was high in the age group of 10 years. If the age increased from 5yrs to 10yrs, infection rate is also increased but infection rate was decreasing from the age of $10 y r s$ to $15 y$ rs.(fig-1)

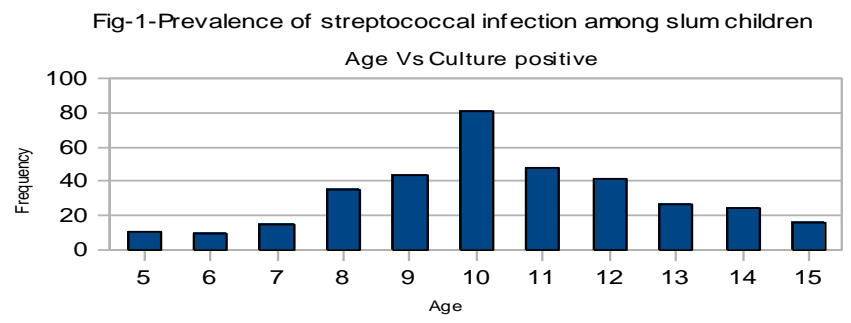

Of the total 321 culture positive's 93 (29\%) were asymptomatic but culture positive's. Of which, 217 children were GAS positive and rest of them positive for other group of streptococcus. Among the GAS isolation, $15 \%$ were asymptomatic, $26 \%$ had tonsillitis only, and $13 \%$ had sore throat. Other group of streptococcus was also isolated as $6 \% \mathrm{GBS}, 9 \% \mathrm{GCS}$ and $1.5 \%$ mixed infection with all group of streptococcus was isolated. (table-3)

\begin{tabular}{|l|c|c|c|c|c|c|c|c|}
\hline Symptoms & GAS & GBS & GCS & GDS & GFS & GGS & Mixed & Culture negative \\
\hline Asymptomatic & 51 & 17 & 18 & 2 & 1 & 1 & 3 & 94 \\
\hline Tonsillitis & 82 & 5 & 1 & 1 & 0 & 0 & 0 & 15 \\
\hline Sore throat & 43 & 4 & 6 & 2 & 0 & 0 & 0 & 28 \\
\hline Cough and cold & 40 & 7 & 25 & 1 & 0 & 1 & 6 & 138 \\
\hline Fever & 1 & 2 & 1 & 0 & 0 & 0 & 0 & 4 \\
\hline Total & $\begin{array}{c}217 \\
(36 \%)\end{array}$ & $\begin{array}{c}35 \\
(6 \%)\end{array}$ & $\begin{array}{c}51 \\
(9 \%)\end{array}$ & $\begin{array}{c}6 \\
(1 \%)\end{array}$ & $\begin{array}{c}1 \\
(.1 \%)\end{array}$ & $\begin{array}{c}2 \\
(.3 \%)\end{array}$ & $\begin{array}{c}9 \\
(1.5 \%)\end{array}$ & $\begin{array}{c}279 \\
(47 \%)\end{array}$ \\
\hline
\end{tabular}


Table-3: Distribution of streptococcal infection among slum children in correlation with symptoms

While comparing Chennai zones with streptococcal isolation, the rate of culture positive was high $(17 \%)$ in zone four followed by zone three $(13 \%)$, one, ten and nine $(11 \%)$ and statistically significant (pvalue 0.000$)$ difference was observed. Isolation of GAS positive was not significantly associated with presence of sore throat (0.219). (table-4)

Table -4: Comparison of ASO positive with sore throat.

\begin{tabular}{|c|c|c|c|c|c|c|}
\hline & \multicolumn{2}{|c|}{ Sore throat } & \multirow[b]{2}{*}{ Total } & \multirow[b]{2}{*}{ p-value } & \multirow{2}{*}{$\begin{array}{l}\text { Odds } \\
\text { Ratio }\end{array}$} \\
\hline & & Present & Absent & & & \\
\hline \multirow{2}{*}{ ASO } & Positive & 42 & 289 & 331 & \multirow{3}{*}{0.124} & \multirow[t]{3}{*}{1.407} \\
\hline & Negative & 25 & 242 & 267 & & \\
\hline \multicolumn{2}{|l|}{ Total } & 67 & 531 & 598 & & \\
\hline
\end{tabular}

\section{Discussion}

In the present study, GAS was isolated in $36 \%$, seems to be very high compare to other studies conducted in India previously. Those studies have reported that the carrier status of GAS was between 2.5$14.3 \%{ }^{1,2}, 8.4 \%$ in Chennai ${ }^{4}, 2.3 \%$ in Vellore. The epidemiological picture of streptococcal infections in India is quite different from that of the developed countries, suggesting that may be some serotypes are much more common than others within a population in different geographical locations. This study reports that the prevalence of GAS was not significantly different between males and females. Studies have reported that the prevalence of $\beta$-haemolytic streptococcal pharengitis was higher among females than among males in Delhi and other places in India ${ }^{6,7}$, others have reported that GAS pharengitis did not vary according to $\operatorname{sex}^{8}$. This study shows that the significant association was not observed while comparing ASO positivity with sore throat; it shows the children may be newly infected with streptococcal group. In the present study, since, all the study populations were from similar socioeconomic status, statistically significant difference was observed only between father's occupation, and zones. It shows that poor income and hygiene conditions of the zone may play a significant role in spread of infection. Presence of other group of $\mathrm{C}$ and $\mathrm{G}$ streptococcus is genetically related to GAS, but the prevalence rate is very low and the clinical symptoms also mimics like GAS infection. ${ }^{9}$ Other group of streptococcus may also carry virulence factor of GAS and is also a driving force for major complication like acute renal failure. To prevent this, awareness should be created to the slum population about the cleanliness, mode of transmission of the disease and also the government should take initiative to overcome this problem by providing clean drinking water, underground drainage system, sufficiently ventilated houses, and proper toilets in the slums.

\section{Limitations}

The positive children did not have any follow up or given any treatment by the researcher. The report was submitted to corporation of Chennai for further action.

\section{Acknowledgement}

We thank our former professors Dr.Manjula Datta and Dr.Jerard Maria Selvam for their support to complete this study. We thank Dr. Guganantham for permitting to conduct this study in Chennai slums. We thank all the children for their participation in the study. We thank The Tamil Nadu Dr.M.G.R.Medical University for their financial support to conduct this study.

\section{Reference}

[1]. Koshi G, Benjamin V. Surveillance of streptococcal infection in children in a South Indian community: a pilot survey. Indian Journal of Medical Research, 1977, 66: 379-388.

[2]. Koshi G, Jadhar M, Myers RM. Streptococcal pharyngitis in children in Southern India. Indian Journal of Medical Research, 1970, 58: $161-165$.

[3]. Gupta R, Prakash K, Kapoor AK. Subclinical streptococcal throat infection in school children. Indian Pediatrics, 1992, 29: 14911494.

[4]. Charmaine A C Lloyd Pharyngeal carriage of group A streptococci in school children in Chennai Indian J Med Res 124:1958. 2006

[5]. Brandt ER, Teh T, Relf Wa, Hobb RI, Good MF. Protective and non protective epitopes from amino termini of M proteins from australian aboriginal isolates and reference strains of Group a streptococci. Infect Immun 2000; 68 : 6587-94.

[6]. Manual of reference procedures in streptococcal bacteriology. New Delhi, WHO Regional Office for South-East Asia, 1987 (unpublished document SEA/HLM/230)

[7]. Reed BD, Huck W, French T. Diagnosis of group A b-hemolytic Streptococcus using clinical scoring criteria, Directigen 1-2-3 group A streptococcal test, and culture. Archives of Internal Medicine, 1990, 150: 1727-1732.

[8]. Sarkar S et al. A study on sore throat and beta-hemolytic streptococcal pharyngitis among rural school children in Varanasi with reference to age and season. Indian Journal of Public Health, 1988, 32: 191-198.

[9]. Lindbaek M, Høiby Ea, Lermark G, Steinsholt IM, Hjortdahl P. Clinical symptoms and signs in sore throat patients with large colony variant beta-haemolytic streptococci groups $\mathrm{C}$ or $\mathrm{G}$ versus group a. Br J Gen Pract 2005; 55 : 615-9. 